\title{
The influence of carbonate complexation on lanthanide/actinide sorption on montmorillonite
}

\author{
By M. Marques Fernandes*, B. Baeyens and M. H. Bradbury \\ Paul Scherrer Institut, Laboratory for Waste Management, 5232 Villigen PSI, Switzerland
}

(Received September 25, 2007; accepted in revised form February 26, 2008)

Actinide surface complexation / Carbonate complexation / Montmorillonite / Sorption modelling

\begin{abstract}
Summary. The safety case for radioactive waste repositories is, to a large extend based on the physical and chemical retention of radionuclides on clay minerals which are important constituents in both the man-made engineered barriers and in argillaceous host rock formations. The presence of carbonate, one of the most important inorganic ligands for lanthanide and actinide ions in groundwaters and clay porewaters, can have a significant influence on their sorption behaviour on clay minerals. The sorption of $\mathrm{Eu}(\mathrm{III})$ on Na-montmorillonite in the absence and the presence of carbonate was investigated in batch sorption experiments. In the presence of carbonate two sets of experimental conditions were investigated. Eu(III) sorption measurements were performed as a function of $\mathrm{pH}$ in equilibrium with atmospheric $p_{\mathrm{CO}_{2}}\left(=10^{-3.5} \mathrm{bar}\right)$ and at a variable $p_{\mathrm{CO}_{2}}\left(=10^{-1.4}\right.$ to $\left.10^{-3.4} \mathrm{bar}\right)$. The sorption data were modelled using the 2 site protolysis non-electrostatic surface complexation and cation exchange model. Both experimental data sets in the presence of carbon could be quantitatively modelled by including in the sorption model two additional surface complexation reactions on the strong sites forming $\equiv \mathrm{S}^{\mathrm{S}} \mathrm{OEuCO}_{3}{ }^{0}$ and $\equiv \mathrm{S}^{\mathrm{S}} \mathrm{OEuOHCO}_{3}{ }^{-}$surface complexes.
\end{abstract}

\section{Introduction}

The physical and chemical retention properties of radionuclides are one of the main pillars upon which the safety case for a deep geological repository is build. A major role in radionuclide retardation is played by the sorption on weathered or secondary phase materials of the waste and engineered barriers around it, and natural minerals in sediments along the transport paths to the biosphere. Surface retention is especially effective in clay minerals with their large surface areas and their strong retention capacity. For this reason, clay-rich host rock formations and back-fill materials are being investigated. Identifying and quantifying the radionuclide uptake processes occurring at the clay/solution interface over a representative range of relevant conditions is indispensable for performance assessment [1-3].

In the past, attempts have been made to develop models which are capable of describing and predicting the sorption of radionuclides on clay minerals over a wide range of

\footnotetext{
*Author for correspondence (E-mail: maria.marques@psi.ch).
}

physico-chemical conditions. The hypothesis behind many of these studies is that by understanding and being able to model sorption on a number of different clay minerals, sorption in natural systems containing significant levels of such clay minerals can be predicted because they provide the major sinks for radionuclides. For example, the 2 site protolysis non electrostatic surface complexation and cation exchange (2SPNE SC/CE) model is a quasi-mechanistic thermodynamic sorption model appropriate for deriving/calculating the uptake of a variety of safety relevant radionuclides onto clay minerals [4-6]. This model has been applied to successfully model the sorption edge and isotherm data of a number of metal ions including $\mathrm{Eu}$ and $\mathrm{Am}$ on $\mathrm{Na}$-, and $\mathrm{Ca}-$ montmorillonites as a function of $\mathrm{pH}$, element concentration and ionic strength [7, 8]. Eu(III) is often used as a chemical analogue for trivalent actinides $\mathrm{Am}$ (III), $\mathrm{Pu}$ (III) and $\mathrm{Cm}$ (III), which make a significant contribution to the radiotoxicity of the radioactive waste.

In natural systems, the predominant aqueous phase reactions of trivalent actinides and lanthanides are hydrolysis and complexation with dissolved inorganic ligands e.g. carbonates. Dissolved inorganic carbon is ubiquitous in natural systems. The formation of carbonate complexes in solution can potentially lead to a decrease in metal ion sorption. Sorption models neglecting the influence of carbonate may either under-predict or over-predict radionuclide sorption of trivalent radionuclides in natural systems. In the present study, the effect of dissolved carbonate on the sorption behaviour of trivalent lanthanides/actinides onto montmorillonite is quantified, and the 2SPNE SC/CE sorption model is applied to derive surface complexation constants of $\mathrm{An}(\mathrm{III}) / \mathrm{Ln}$ (III)-carbonate/hydroxycarbonate complexes. Because of the very close thermodynamic properties, Eu(III) was used as a representative for trivalent lanthanides and actinides. The main goal is to extend the currently available thermodynamic models for trivalent radionuclide sorption (Eu(III)/Am(III)/Cm(III)/Pu(III)) onto clay minerals by including the influence of carbonate complexation on actinide sorption.

\section{Sorption model}

Sorption data obtained in this work were modelled using the 2SPNE SC/CE model. This model describes sorption 
by a combination of electrostatic binding at cation exchange sites [9] and inner-sphere surface complexation at aluminol and/or silanol group edge sites [10]. The 2SPNE SC/CE model and the modelling procedure have been described in detail on many occasions [4-7] and only a brief outline is given below.

\section{Cation exchange}

The permanent negative charge on clay mineral surfaces, arising from isomorphous substitution, is compensated by an excess of aqueous cations held closely around the outside of the Si-Al-Si units by electrostatic attraction. In principle, the sorption due to cation exchange is independent of $\mathrm{pH}$. Cation exchange reactions of trivalent free cations $\mathrm{An}^{3+}$ onto homo-ionic clay minerals in the $\mathrm{Na}$ or $\mathrm{Ca}$ forms can be expressed as:

$$
3 \mathrm{Me}^{z+} \text {-clay }+z \mathrm{An}^{3+} \Leftrightarrow z \mathrm{An}^{3+} \text {-clay }+3 \mathrm{Me}^{z+},
$$

where $\mathrm{Me}=\mathrm{Na}^{+}$or $\mathrm{Ca}^{2+}$ and $z$ is the corresponding valency.

By application of the mass action law, a selectivity coefficient ${ }_{\mathrm{Me}}^{\mathrm{An}} K_{c}$ can be calculated [11]:

$$
{ }_{\mathrm{Me}}^{\mathrm{An}} K_{c}=\frac{N_{\mathrm{An}}^{z}}{N_{\mathrm{Me}}^{3}} \frac{\{\mathrm{Me}\}^{3}}{\{\mathrm{An}\}^{z}}
$$

where $N_{\mathrm{An}}$ and $N_{\mathrm{Me}}=$ the equivalent fractional occupancies, defined as the equivalents of An (or Me) sorbed per unit mass divided by the cation exchange capacity (CEC) in eq $\mathrm{kg}^{-1} ;\{\}=$ aqueous activities. that:

At trace sorbate concentrations $N_{\mathrm{Me}} \sim 1$ and it follows

$$
{ }_{\mathrm{Me}}^{\mathrm{An}} K_{c}={ }^{\mathrm{An}} R_{\mathrm{d}}{ }^{z} \frac{3^{z}}{\mathrm{CEC}^{z}}[\mathrm{Me}]^{3} \frac{\gamma_{\mathrm{Me}}^{3}}{\gamma_{\mathrm{An}}^{z}}
$$

where $R_{\mathrm{d}}=$ the solid liquid distribution ratio $\left(\mathrm{L} \mathrm{kg}^{-1}\right)$, [ ] = aqueous concentrations $\left(\mathrm{mol} \mathrm{L}^{-1}\right)$ and $\gamma=$ activity coefficients $\left(\mathrm{L} \mathrm{mol}^{-1}\right)$.

\subsection{Surface complexation}

The $\mathrm{pH}$ dependent component of sorption on montmorillonite is described by sorbate uptake on the amphoteric surface hydroxyl groups ( $\equiv \mathrm{SOH}$ sites) situated at clay platelet edges. Surface complexation reactions have been characterized in terms of protonation and deprotonation on two type of weak ( $\left.\equiv \mathrm{S}^{\mathrm{W} 1,2} \mathrm{OH}\right)$ sites, and metal binding to strong sites $\left(\equiv \mathrm{S}^{\mathrm{S}} \mathrm{OH}\right)$ and one weak site $\left(\equiv \mathrm{S}^{\mathrm{w} 1} \mathrm{OH}\right)[5]$. The $\equiv \mathrm{S}^{\mathrm{W} 1} \mathrm{OH}$ and $\equiv \mathrm{S}^{\mathrm{W} 2} \mathrm{OH}$ sites have the same capacities but different protolysis constants. The protolysis constants of the $\equiv \mathrm{S}^{\mathrm{S}} \mathrm{OH}$ type sites are assumed to be the same as the protolysis constants of $\equiv \mathrm{S}^{\mathrm{W} 1} \mathrm{OH}$ sites. Surface complexation reactions occur predominantly on these sites. The $\equiv \mathrm{S}^{\mathrm{S}} \mathrm{OH}$ sites have a much smaller capacity but form considerably stronger complexes with metals and dominate the sorption at trace concentrations. Non-adjustable parameters such as site capacities and protolysis constants determined for Na-SWy-1 [5] are summarized in Table 1. A surface complexation reaction representing for example, the sorption of
Table 1. Summary of the non-adjustable parameters: cation exchange capacities (CEC), surface hydroxyl group capacities and protolysis constants for SWy-1 montmorillonite [5].

\begin{tabular}{ll}
\hline Site types & Site capacities $\left(\mathrm{mol} \mathrm{kg}^{-1}\right)$ \\
\hline$\equiv \mathrm{S}^{\mathrm{S}} \mathrm{OH}$ & $2.0 \times 10^{-3}$ \\
$\equiv \mathrm{S}^{\mathrm{W} 1, \mathrm{~W} 2} \mathrm{OH}$ & $4.0 \times 10^{-2}$ \\
$\mathrm{CEC}$ & $8.7 \times 10^{-1} \mathrm{eq} \mathrm{kg}^{-1}$ \\
\hline Protolysis reactions & $\log K_{\text {protolysis }}$ \\
\hline$\equiv \mathrm{S}^{\mathrm{S}, \mathrm{W} 1} \mathrm{OH}+\mathrm{H}^{+} \Leftrightarrow \equiv \mathrm{S}^{\mathrm{S}, \mathrm{W}_{1}} \mathrm{OH}_{2}{ }^{+}$ & 4.5 \\
$\equiv \mathrm{S}^{\mathrm{S}, \mathrm{W} 1} \mathrm{OH} \Leftrightarrow \equiv \mathrm{S}^{\mathrm{S}, \mathrm{W}_{1}} \mathrm{O}^{-}+\mathrm{H}^{+}$ & -7.9 \\
$\equiv \mathrm{S}^{\mathrm{W} 2} \mathrm{OH}+\mathrm{H}^{+} \Leftrightarrow \equiv \mathrm{S}^{\mathrm{W}_{2}} \mathrm{OH}_{2}^{+}$ & 6.0 \\
$\equiv \mathrm{S}^{\mathrm{W} 2} \mathrm{OH} \Leftrightarrow \equiv \mathrm{S}^{\mathrm{W} 2} \mathrm{O}^{-}+\mathrm{H}^{+}$ & -10.5 \\
\hline
\end{tabular}

a trivalent metal $\left(\mathrm{An}^{3+}\right)$ on the strong sites may be written generally as:

$$
\begin{aligned}
\equiv \mathrm{S}^{\mathrm{S}} \mathrm{OH}+\mathrm{An}^{3+} & +x \mathrm{H}_{2} \mathrm{O} \Leftrightarrow \\
& \equiv \mathrm{S}^{\mathrm{S}} \mathrm{OAn}(\mathrm{OH})_{x}{ }^{3-(x+1)}+(x+1) \mathrm{H}^{+}
\end{aligned}
$$

In a non-electrostatic model, the corresponding surface complexation constant, ${ }^{\mathrm{s}} K_{x}$, can be expressed as:

$$
{ }^{\mathrm{s}} K_{x}=\frac{\left[\equiv \mathrm{S}^{\mathrm{S}} \mathrm{OAn}(\mathrm{OH})_{x}{ }^{3-(x+1)}\right]}{\left[\equiv \mathrm{S}^{\mathrm{S}} \mathrm{OH}\right]} \frac{\left\{\mathrm{H}^{+}\right\}^{(x+1)}}{\left\{\mathrm{An}^{3+}\right\}},
$$

where \{\} terms are aqueous activities and [ ] terms are concentrations. A major feature of the 2SPNE SC/CE model is that no electrostatic term is required in the mass action equations describing protolysis and surface complexation reactions, to reproduce the experimental data. In previous studies it became apparent in trying to model a whole range of $\mathrm{pH}$ titration data, sorption edge and isotherms, that this electrostatic term is of second order importance in the ability of calculations to reproduce the measured data [5, 12].

MINSORB [5], is a computer code used to model the sorption data. MINSORB is basically the geochemical code MINEQL [13] containing subroutines for calculating cation exchange and surface complexation reactions. In order to model the influence of carbonate on the sorption of $\mathrm{Eu}$ on SWy-1, carbonate complexation constants had to be included in the modelling. Metal hydrolysis and carbonate

\begin{tabular}{|c|c|}
\hline Hydrolysis reactions & $\log K_{0}$ \\
\hline $\begin{array}{l}\mathrm{An}^{3+}+\mathrm{H}_{2} \mathrm{O} \Leftrightarrow \mathrm{AnOH}^{2+}+\mathrm{H}^{+} \\
\mathrm{An}^{3+}+2 \mathrm{H}_{2} \mathrm{O} \Leftrightarrow \mathrm{An}(\mathrm{OH})_{2}{ }^{+}+2 \mathrm{H}^{+} \\
\mathrm{An}^{3+}+3 \mathrm{H}_{2} \mathrm{O} \Leftrightarrow \mathrm{An}(\mathrm{OH})_{3}{ }^{0}+3 \mathrm{H}^{+}\end{array}$ & $\begin{array}{r}-7.2 \pm 0.5 \\
-15.1 \pm 0.7 \\
-26.2 \pm 0.5\end{array}$ \\
\hline Carbonate complexation reactions & $\log K_{0}$ \\
\hline $\begin{array}{l}\mathrm{An}^{3+}+\mathrm{CO}_{3}{ }^{2-} \Leftrightarrow \mathrm{AnCO}_{3}{ }^{+} \\
\mathrm{An}^{3+}+2 \mathrm{CO}_{3}{ }^{2-} \Leftrightarrow \mathrm{An}\left(\mathrm{CO}_{3}\right)_{2}{ }^{-} \\
\mathrm{An}^{3+}+3 \mathrm{CO}_{3}{ }^{2-} \Leftrightarrow \mathrm{An}\left(\mathrm{CO}_{3}\right)_{3}{ }^{3-}\end{array}$ & $\begin{array}{r}8.0 \pm 0.4 \\
12.9 \pm 0.6 \\
15.0 \pm 1.0\end{array}$ \\
\hline
\end{tabular}
complexation constants were taken from the Am(III) NEATDB Chemical Thermodynamic Database $[14,15]$ and are summarized in Table 2.

Table 2. Hydrolysis and carbonate complexation constants used in the sorption modelling $[14,15]$. 


\section{Experimental}

\subsection{Materials}

Supra-pure grade chemicals and ultra pure deionised water were used to prepare solutions. SWy-1 montmorillonite was taken for the sorption investigations after conversion into the Na-form. The clay mineral preparation procedures have been described in detail elsewhere [16] and only an outline will be given here. A purifying procedure was applied to the "as received" powder to obtain, as far as possible, a single phased suspension of Na-montmorillonite in a 1 : 1 background electrolyte. SWy-1 montmorillonite was washed three times with $1 \mathrm{M} \mathrm{NaClO}$ to remove all soluble salts and/or sparingly soluble minerals such as calcite and to convert the clay into the homo-ionic Na-form. Sepa-

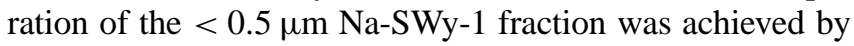
successive washing with de-ionised water pre-equilibrated with a small quantity of montmorillonite. After allowing the montmorillonite to peptise for $\sim 15 \mathrm{~min}$ and centrifuging for $\sim 7 \mathrm{~min}$ at $\sim 600 \mathrm{~g}(\max )$, the Na-Swy-1 fraction in the supernatant solution $(<0.5 \mu \mathrm{m})$ was transferred into a large polyethylene container. A fresh $1 \mathrm{M} \mathrm{NaClO}_{4}$ solution was then immediately added in order to flocculate the fine clay particles and to prevent hydrolysis. Soluble hydroxyaluminium compounds were removed by an acid treatment $(\mathrm{pH} \mathrm{3.5,1} \mathrm{h)} \mathrm{followed} \mathrm{by} \mathrm{phase} \mathrm{separation} \mathrm{and} \mathrm{neutralisa-}$ tion with $1 \mathrm{M} \mathrm{NaClO}_{4}(\mathrm{pH}$ 7). Batches were prepared in $0.1 \mathrm{M} \mathrm{NaClO}_{4}$ from the stock suspension for the sorption experiments by the dialysis technique. The clay content in the final suspensions was determined by heating weighed aliquots to constant weight at $105^{\circ} \mathrm{C}$ and correcting for the salt content. The cation exchange capacity CEC, determined using the ${ }^{22} \mathrm{Na}$ isotopic dilution method was $0.870 \pm$ $0.035 \mathrm{eq} \mathrm{kg}^{-1}[16,17]$.

\subsection{Batch sorption experiments of $\mathrm{Eu}(\mathrm{III})$ on Na-SWy-1}

Carbonate free experiments were performed in a glove box under $\mathrm{N}_{2}$-atmosphere $\left(\mathrm{O}_{2}<3 \mathrm{ppm}\right)$. Experiments in the presence of carbonate were carried out under atmospheric conditions. Sorption experiments on conditioned and purified Na-SWy-1 montmorillonite at trace radionuclide concentration $\left(\mathrm{Eu}_{\mathrm{TOT}}<2 \times 10^{-9} \mathrm{M}\right)$ were carried out at fixed ionic strength $(I=0.1 \mathrm{M})$ and at a solid to liquid $(\mathrm{S} / \mathrm{L})$ ratio $\sim 1 \mathrm{~g} \mathrm{~L}^{-1}$ in $40 \mathrm{~mL}$ polypropylene centrifuge tubes. Experiments were carried out as a function of $\mathrm{pH}$ and $p_{\mathrm{CO}_{2}}$. Two sets of experiments were performed: (i) $\mathrm{Eu}$ (III) sorption as a function of $\mathrm{pH}$ in equilibrium with the $p_{\mathrm{CO}_{2}}$ of the air $\left(p_{\mathrm{CO}_{2}}=10^{-3.5}\right.$ bar), denoted as "fixed $p_{\mathrm{CO}_{2}}$ " (Table 3a) and (ii) $\mathrm{Eu}$ (III) sorption in $20 \mathrm{mM} \mathrm{NaHCO}$ as a function of $\mathrm{pH}$ denoted as "variable $p_{\mathrm{CO}_{2}}$ " (Table $3 \mathrm{~b}$ ). The latter experiments are not in equilibrium with the air atmosphere and were carried out in a closed system. In both cases, the total carbonate concentration was adjusted as a function of $\mathrm{pH}$ using $\mathrm{NaHCO}_{3} / \mathrm{Na}_{2} \mathrm{CO}_{3}$ solutions reproducing the different $p_{\mathrm{CO}_{2}}$. The $\mathrm{pH}$ values of the carbonate free experiments, and, the experiments at varying $p_{\mathrm{CO}_{2}}$ (closed systems), were buffered with MOPS, TRIS or CHES buffers at concentrations of $2 \times 10^{-3} \mathrm{M}[8,18]$. After labelling with ${ }^{152} \mathrm{Eu}$ and shaking end-over-end for $7 \mathrm{~d}$, the suspensions were cen-
Table 3. Overview of the experimental conditions for Eu(III) sorption on Na-SWy-1 in the presence of carbonate.

(a) Fixed $p_{\mathrm{CO}_{2}}$, in equilibrium with the atmosphere $\left(10^{-3.5}\right.$ bar $)$

\begin{tabular}{rcc}
\hline $\mathrm{pH}$ & TIC $(\mathrm{mM})$ & Ionic strength $(\mathrm{M})$ \\
7.0 & 0.06 & 0.1 \\
7.5 & 0.19 & 0.1 \\
8.0 & 0.61 & 0.1 \\
8.5 & 1.98 & 0.1 \\
9.2 & 7.43 & 0.1 \\
9.7 & 28.75 & 0.1 \\
10.3 & 302.00 & 0.5 (not modelled) \\
\hline
\end{tabular}

(b) Variable $p_{\mathrm{CO}_{2}}$ (calculated)

\begin{tabular}{ccc}
\hline $\mathrm{pH}$ & $\mathrm{TIC}(\mathrm{mM})$ & $p_{\mathrm{CO}_{2}}($ bar $)$ \\
7.4 & 20 & $10^{-1.4}$ \\
8.3 & 20 & $10^{-2.3}$ \\
9.3 & 20 & $10^{-3.4}$ \\
\hline
\end{tabular}

trifuged at $105000 \mathrm{~g}(\max )$ for one hour using a Beckman Coulter Avanti ${ }^{\mathrm{TM}}$ J30I High Performance Centrifuge. Carbonate free samples were returned to the glove box for sampling of the supernatant and $\mathrm{pH}$ measurements, whereas the samples in the presence of carbonate were measured under atmospheric conditions. All experiments were carried out in triplicate. The total inorganic carbon (TIC) concentrations in the samples were confirmed by TIC measurements using a Dohrmann Carbon Analyser. Kinetic experiments performed for time periods between 2 and $60 \mathrm{~d}$ showed that equilibrium conditions were already reached after $2 \mathrm{~d}$. Radiochemical assays of ${ }^{152} \mathrm{Eu}$ in the supernatants were performed using a Canberra Packard Cobra Quantum Gamma counter together with standard labelled solutions.

The results of the batch sorption experiments are expressed in terms of the logarithm of the distribution ratio, $R_{\mathrm{d}}$, plotted against $\mathrm{pH} . R_{\mathrm{d}}$ is defined in the customary manner as:

$$
R_{\mathrm{d}}=\frac{\left(C_{\mathrm{init}}-C_{\mathrm{eq}}\right)}{C_{\mathrm{eq}}} \frac{V}{m},
$$

where $C_{\text {init }}$ is the initial aqueous concentration of active and inactive metal $\left(\mathrm{mol} \mathrm{L}^{-1}\right), C_{\mathrm{eq}}$ is the equilibrium aqueous concentration of active and inactive metal $\left(\mathrm{mol} \mathrm{L}^{-1}\right), V$ is the volume of liquid phase (L), and $m$ is the mass of solid phase (kg).

\section{Results and discussions}

The uptake of $\mathrm{Eu}(\mathrm{III})$ at trace concentration as a function of $\mathrm{pH}$ on Na-montmorillonite in the absence and the presence of carbonate at a fixed $p_{\mathrm{CO}_{2}}$ (atmospheric conditions) and variable $p_{\mathrm{CO}_{2}}$ (closed systems) are shown in Figs. 1 and 2 respectively. In the absence of carbonate the sorption of $\mathrm{Eu}$ increases as a function of $\mathrm{pH}$ and remains constant above $\mathrm{pH} \sim 8$ at a high value $\left(\log R_{\mathrm{d}}=6 \pm 0.2 \mathrm{~L} \mathrm{~kg}^{-1}\right)$. In both of the cases where carbonate is present there is a clear effect on Eu sorption.

In the experiments at a constant $p_{\mathrm{CO}_{2}}=10^{-3.5}$ bar (Fig. 1, Table 3a) no influence of the presence of carbonate is ob- 


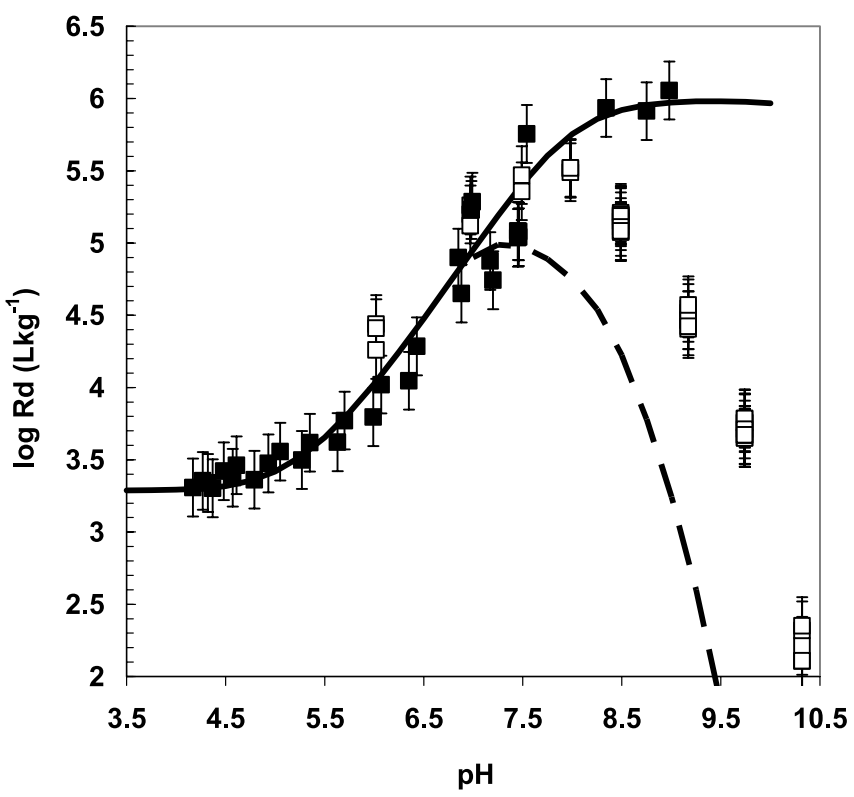

Fig. 1. Eu sorption measurements on Na-SWy-1. (ם) Sorption edge measurements in the absence of carbonate. Continuous black line: modelled curve using 2SPNE SC/CE model with parameters given in Tables 1, 2 and 4. ( $\square$ ) Eu sorption measurements in equilibrium with atmospheric $p_{\mathrm{CO}_{2}}=10^{-3.5}$ bar. Dashed black line: modelled curve assuming that aqueous Eu carbonate complexes do not sorb.

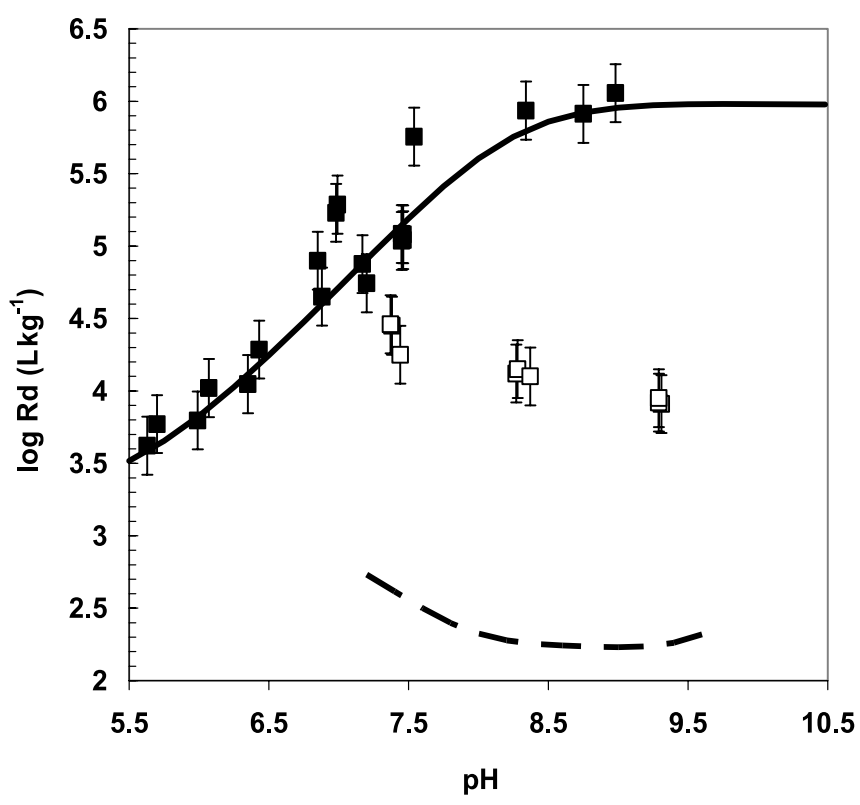

Fig. 2. Eu sorption measurements onto Na-SWy-1. (ם) Sorption edge measurements in the absence of carbonate. Continuous black line: modelled curve. ( $\square) \mathrm{Eu}$ sorption measurements at variable $p_{\mathrm{CO}_{2}}$. Dashed black line: modelled curve assuming that aqueous Eu carbonate complexes do not sorb.

served up to $\mathrm{pH} \sim 8$. The $\log R_{\mathrm{d}}$ values are close to those measured in the carbonate-free system $\left(\log R_{\mathrm{d}}=5.6 \pm\right.$ $0.2 \mathrm{~L} \mathrm{~kg}^{-1}$ ). However, at $\mathrm{pH}$ values greater than 8 , a pronounced decrease in the Eu sorption is observed with increasing $\mathrm{pH}$ and carbonate concentration (Table 3a). The $\log R_{\mathrm{d}}$ value decreases to $\sim 2.0 \pm 0.2\left(\mathrm{~L} \mathrm{~kg}^{-1}\right)$ at $\mathrm{pH} \sim 10.3$. At variable $p_{\mathrm{CO}_{2}}$, the effect of dissolved $\mathrm{CO}_{2}$ on Eu sorption is already evident from $\mathrm{pH} 7.4$ and higher. The carbonate concentrations under these circumstances are generally
Table 4. Summary of the surface complexation constants and selectivity coefficient characterizing the sorption of $\mathrm{Eu}(\mathrm{III})$ in the absence of carbonate at trace concentrations on Na-SWy-1.

Surface complexation reactions

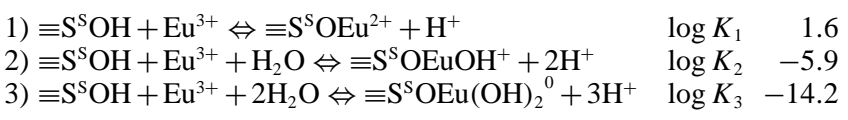

Cation exchange reaction

CE: $3 \mathrm{Na}-$ clay $+\mathrm{Eu}^{3+} \Leftrightarrow \mathrm{Eu}-\mathrm{clay}+3 \mathrm{Na}^{+} \quad K_{\mathrm{c}} \quad 29$

greater (see Table 3b). At pH 7.4 the $\log R_{\mathrm{d}}$ is about $4.5 \pm$ $0.2 \mathrm{~L} \mathrm{~kg}^{-1}$, and, decreases to $3.9 \pm 0.2 \mathrm{~L} \mathrm{~kg}^{-1}$ at $\mathrm{pH} 9.3$. It should be noted that consistent results ( $R_{\mathrm{d}}$ values) are found for the two set of experimental data in the presence of carbonate around $\mathrm{pH} 9.3$ which correlates with similar TIC concentrations ( $\operatorname{similar} p_{\mathrm{CO}_{2}}$ ).

The $\mathrm{Eu}(\mathrm{III})$ sorption data on $\mathrm{Na}-\mathrm{SWy}-1$ in the absence of carbonate were modelled with the 2SPNE SC/CE model using the non-adjustable parameters given in Table 1 and the hydrolysis data from Table 2. The surface complexation reactions and associated stability constants are given in Table 4. An Eu-Na exchange reaction with a selectivity coefficient $\left(K_{\mathrm{c}}=29\right)$ was included in the modelling. Sorption is considered to take place only on the strong surface sites since experiments were performed at trace concentrations. The result of the model calculations are shown in Figs. 1 and 2 by the continuous lines.

In a first attempt to model the sorption edges of $\mathrm{Eu}(\mathrm{III})$ on Na-montmorillonite in the presence of carbonate using the 2SPNE SC/CE model, it was assumed that only the surface complexation reactions given in Table 4 were taking place on the clay surface i.e. Eu(III) carbonate complexes were treated as being non-sorbing. The results of this modelling approach failed to reproduce the experimental results of both data sets (dashed black lines in Figs. 1 and 2). The modelled effect of the influence of carbonate on the sorption is significantly greater than the effect in the experimental data. Any influence of the precipitation of solid phases such as $\mathrm{EuOHCO}_{3}$ (cr) $\left(\log K_{0 \mathrm{sp}}\right.$ for $\mathrm{AmOHCO}_{3}(\mathrm{cr})=-22.7 \pm 0.4$ [15]) or $\mathrm{NaEu}\left(\mathrm{CO}_{3}\right)_{2}$ $\left(\log K_{0 \text { sp }}\right.$ for $\mathrm{NaAm}\left(\mathrm{CO}_{3}\right)_{2}=-21.0 \pm 0.5$ [15]) can be excluded at the $\mathrm{Eu}(\mathrm{III})$ concentration used in the experiments $\left(\sim 2 \times 10^{-9} \mathrm{~mol} \mathrm{~L}^{-1}\right)$. Consequently, other surface sorption reactions must be involved.

Fig. 3 presents the aqueous speciation for $\mathrm{Eu}(\mathrm{III})$ at a fixed $p_{\mathrm{CO}_{2}}=10^{-3.5}$ bar in the $\mathrm{pH}$ range 5-10 in $0.1 \mathrm{M}$ $\mathrm{NaClO}_{4}$ as calculated with the thermodynamic data given in Table 2 . At $\mathrm{pH}$ values above 7 , it can be clearly seen that the Eu-mono/-dicarbonate complexes are dominant. In the modelling of the influence of carbonate on sorption, a stepwise approach was adopted by considering, in sequence, simple chemically reasonable surface complexation reactions involving Eu(III) carbonate complexes. The calculated aqueous speciation for Eu(III) under the investigated experimental conditions was used to guide the choice of the surface complexes. 


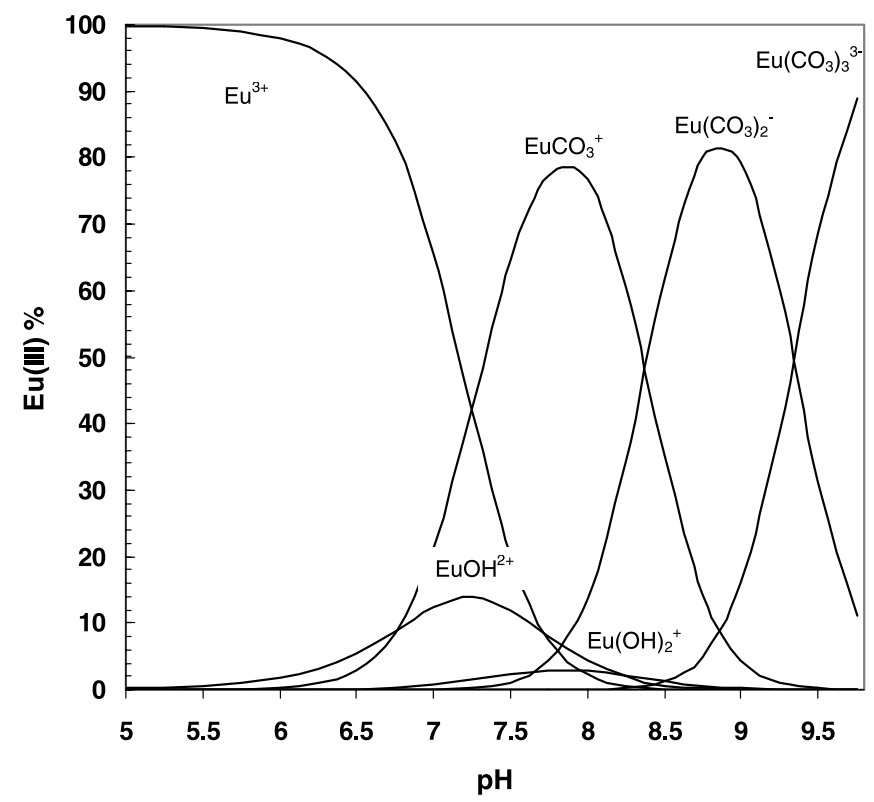

Fig. 3. $\mathrm{Eu}(\mathrm{III})$ speciation as a function of $\mathrm{pH}$ in $0.1 \mathrm{M} \mathrm{NaClO}_{4}$ at $p_{\mathrm{CO}_{2}}=10^{-3.5}$ bar. Total $[\mathrm{Eu}]=2 \times 10^{-9} \mathrm{M}$.

In the first step, the sorption of the Eu-monocarbonate complex $\left(\mathrm{EuCO}_{3}{ }^{+}\right)$on montmorillonite was considered in the $\mathrm{pH}$ range 7-8.5. In this $\mathrm{pH}$ region, $\mathrm{EuCO}_{3}{ }^{+}$is the dominant aqueous species (Fig. 3). Modelling the sorption of $\mathrm{Eu}(\mathrm{III})$ with the surface reaction:

$$
\equiv \mathrm{S}^{\mathrm{S}} \mathrm{OH}+\mathrm{Eu}^{3+}+\mathrm{CO}_{3}{ }^{2-} \Leftrightarrow \equiv \mathrm{S}^{\mathrm{S}} \mathrm{OEuCO}_{3}{ }^{0}+\mathrm{H}^{+},
$$

only part of the sorption edge could be fitted. In a next step, the sorption of the subsequent aqueous $\mathrm{Eu}(\mathrm{III})$ carbonate complexes were integrated in the modeling procedure using the following surface reactions:

$$
\begin{aligned}
& \equiv \mathrm{S}^{\mathrm{S}} \mathrm{OH}+\mathrm{Eu}^{3+}+2 \mathrm{CO}_{3}{ }^{2-} \Leftrightarrow \equiv \mathrm{S}^{\mathrm{S}} \mathrm{OEu}\left(\mathrm{CO}_{3}\right)_{2}{ }^{2-}+\mathrm{H}^{+} \\
& \equiv \mathrm{S}^{\mathrm{S}} \mathrm{OH}+\mathrm{Eu}^{3+}+3 \mathrm{CO}_{3}{ }^{2-} \Leftrightarrow \equiv \mathrm{S}^{\mathrm{S}} \mathrm{OEu}\left(\mathrm{CO}_{3}\right)_{3}{ }^{4-}+\mathrm{H}^{+}
\end{aligned}
$$

Inclusion of the latter surface complexation reactions (Eqs. (2), (3)) allowed the experimental data set at fixed $p_{\mathrm{CO}_{2}}\left(=10^{-3.5}\right.$ bar, Table $\left.3 \mathrm{a}\right)$ to be reproduced. However, the data set at variable $p_{\mathrm{CO}_{2}}$ (Table $3 \mathrm{~b}$ ) could not be modelled. In order to ensure any credibility to surface complexation modeling, more than one set of experimental data must be reproducible with the same set of surface complexation reactions and constants.

In a second modeling approach the Eu sorption data sets were fitted using the aqueous Eu-monocarbonate complex and the inclusion of an Eu-hydroxycarbonate surface complex i.e.

$$
\begin{aligned}
\equiv \mathrm{S}^{\mathrm{S}} \mathrm{OH}+\mathrm{Eu}^{3+}+\mathrm{CO}_{3}{ }^{2-} & +\mathrm{H}_{2} \mathrm{O} \Leftrightarrow \\
& \equiv \mathrm{S}^{\mathrm{S}} \mathrm{OEuOHCO}_{3}{ }^{-}+2 \mathrm{H}^{+} .
\end{aligned}
$$

Including this surface reaction into the model, together with reaction (1), and some "fine tune", allowed both experimental data sets together to be successfully reproduced with the same set of parameters. These surface complexation reac-
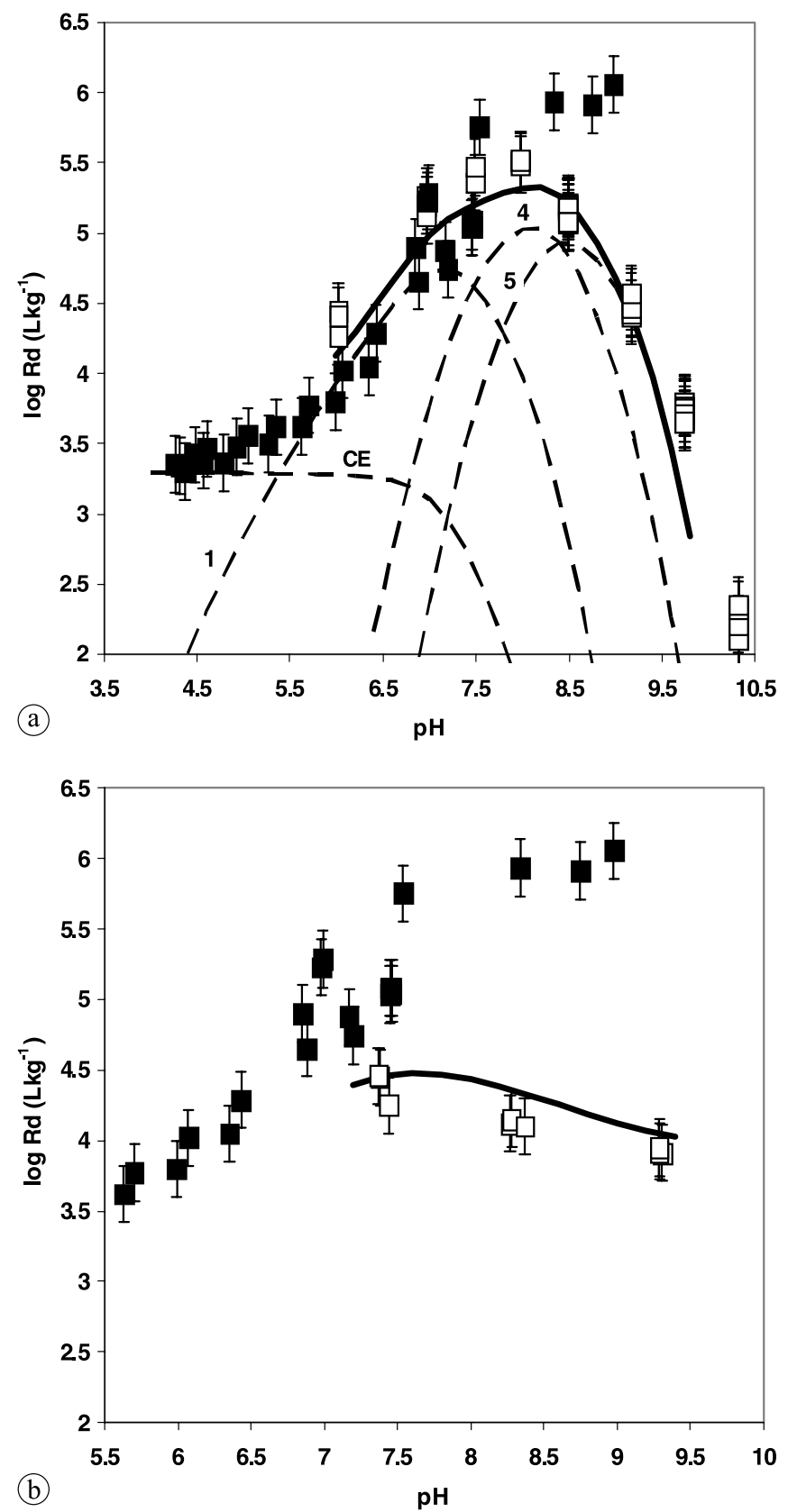

Fig. 4. (a) Measured Eu sorption onto Na-montmorillonite (SWy-1) in the presence of carbonate $p_{\mathrm{CO}_{2}}=10^{-3.5} \mathrm{bar}(\square)$. Continuous black line: modelled curve using 2SPNE SC/CE model with parameters given in Tables 1, 2, 4 and 5. Contribution to the overall sorption in the presence of carbonate of the major individual Eu surface species: $\mathrm{CE}-\mathrm{Eu}^{3+}$, $1: \equiv \mathrm{S}^{\mathrm{S}} \mathrm{OEu}^{2+}, 4: \equiv \mathrm{S}^{\mathrm{S}} \mathrm{OEuCO}_{3}{ }^{0}, 5: \equiv \mathrm{S}^{\mathrm{S}} \mathrm{OEuOHCO}_{3}{ }^{-}$. (b) Measured Eu sorption onto Na-montmorillonite (SWy-1) in the presence of carbonate at variable $p_{\mathrm{CO}_{2}}(\square)$ and modelled sorption in the presence of carbonate (continuous black line).

tions with their corresponding stability constants are summarized in Table 5.

The results of the modelling of both experimental data sets are shown in Figs. $4 \mathrm{a}$ and $4 \mathrm{~b}$. The former shows the contribution to the overall sorption of the major individual $\mathrm{Eu}$ surface species as a function of $\mathrm{pH}$ for constant $p_{\mathrm{CO}_{2}}$ of $10^{-3.5}$ bar. However, it should be noted that the choice of a surface complex involving the neutral Euhydroxycarbonate species is rather peculiar since it is known that under the present experimental conditions this species plays no role in the aqueous $\mathrm{Eu}(\mathrm{III})$ carbonate specia- 
Table 5. Summary of the surface complexation constants describing the sorption of Eu(III) in the presence of carbonate at trace concentrations on Na-SWy-1.

\begin{tabular}{lcc}
\hline 4$) \equiv \mathrm{S}^{\mathrm{S}} \mathrm{OH}+\mathrm{Eu}^{3+}+\mathrm{CO}_{3}{ }^{2-} \Leftrightarrow \equiv \mathrm{S}^{\mathrm{S}} \mathrm{OEuCO}_{3}{ }^{0}+\mathrm{H}^{+}$ & $\log K_{\mathrm{C} 1}$ & 8.3 \\
$5) \equiv \mathrm{S}^{\mathrm{S}} \mathrm{OH}+\mathrm{Eu}^{3+}+\mathrm{CO}_{3}{ }^{2-}+\mathrm{H}_{2} \mathrm{O} \Leftrightarrow \equiv \mathrm{S}^{\mathrm{S}} \mathrm{OEuOHCO}_{3}{ }^{-}+2 \mathrm{H}^{+}$ & $\log K_{\mathrm{C} 2}$ & -0.25 \\
\hline
\end{tabular}

tion $(\log \beta<11$ in 1 molal $\mathrm{NaCl})[14,15,19])$. On the other hand, more thermodynamic data is available for the $\mathrm{EuOHCO}_{3}$ solid phase which can exist in the amorphous or crystalline form, and reliable solubility data have been derived for this compound [15].

The modelling procedure given above allows the Eu(III) sorption on Na-montmorillonite to be quantitatively described under a broad range of conditions $\left(\mathrm{pH}, p_{\mathrm{CO}_{2}}\right)$. However no information can be given about the physicochemical nature of the surface binding: chemical (innersphere complex) or electrostatic binding (outer-sphere complex). Some structural data on the sorption of trivalent actinides and lanthanides for carbonate free systems have been obtained by means of spectroscopic techniques. The sorption of $\mathrm{Eu}(\mathrm{III})$ and $\mathrm{Cm}(\mathrm{III})$ on montmorillonite, illite and kaolinite has been investigated by time resolved laser fluorescence spectroscopy (TRLFS) as a function of $\mathrm{pH}$ in the absence of $\mathrm{CO}_{2}[20,21]$. The structure of $\mathrm{Am}(\mathrm{III})$ sorbed on smectite and kaolinite at varying $\mathrm{pH}$ was analyzed using combined TRLFS and X-ray absorption spectroscopy (XAS). However, the XAS data alone could not unambiguously prove the inner-sphere character of the sorption of $\mathrm{Am}(\mathrm{III})$ on these clay minerals, since only the first Am-O shell could be obtained from the data [21]. For lanthanide/actinide carbonate-clay mineral systems, no reliable thermodynamic and structural data are available. A TRLFS study by Stumpf (2002) [22] underlined the possibility that ternary carbonato surface complexes are formed for $\mathrm{Eu}(\mathrm{III})$ on smectite and kaolinite under air equilibrated conditions. The evidence is based on the differences observed in the fluorescence spectra and fluorescence emission lifetimes of sorbed $\mathrm{Eu}(\mathrm{III})$ in the presence and absence of carbonate. The influence of anions, and in particular carbonate $\left(p_{\mathrm{CO}_{2}}=10^{-3.5}\right.$ bar $)$ on the sorption of Am(III) on smectite has been investigated by Nolin (1997) [23]. Only one $p_{\mathrm{CO}_{2}}$ partial pressure was investigated. In this study the influence of carbonate on the sorption behaviour of Am(III) was modelled by assuming that the Am/carbonate complexes do not sorb on the clay surface. However, the data could only be fitted by assuming that the equilibrium of the Am(III) clay suspension with the atmosphere was not completely achieved and that $p_{\mathrm{CO}_{2}}$ was about $10^{-3.9}$ bar.

\section{Conclusion}

The aim of this work was to characterize and quantify the influence of carbonate on the sorption of $\mathrm{Eu}(\mathrm{III})$ on $\mathrm{Na}$ montmorillonite. The sorption behaviour of Eu(III) under different $p_{\mathrm{CO}_{2}}$ conditions on Na-SWy-1 could be successfully quantitatively described with the 2SPNE SC/CE model. Two additional surface complexation reactions involving Eu-carbonate and Eu-hydroxycarbonate complexes were required to model the data in the presence of dis- solved $\mathrm{CO}_{2}$. In order to increase the credibility to the current "quasi-mechanistic" sorption model, further investigations are necessary. The application of surface analysis techniques such as XAS and TRLFS are planned and might allow the structure of the postulated surface $\mathrm{Eu}(\mathrm{III})$ (hydroxy)carbonate species to be identified.

Acknowledgment. We would like to thank A. Schaible for technical assistance. This work was carried out in the framework of an EURATOM Intra-European Fellowship (EIF) and was co-financed by the EU $6^{\text {th }}$ Framework Integrated Project NF-PRO (contract number F16WCT-2003-02389). Partial financial support was provided by NAGRA (Switzerland).

\section{References}

1. ANDRA: Référentiel géologique du site de Meuse/Haute Marne. Rapp. A RP ADS 99-005 de l'Agence nationale pour la gestion des déchets radioactifs, Châtenay-Malabry, France (2001).

2. NAGRA: Project Opalinus Clay: Safety Report. Demonstration of disposal feasibility (Entsorgungsnachweis) for spent fuel, vitrified high-level waste and long-lived intermediate-level waste. NAGRA Technical Report NTB 02-05, NAGRA, Wettingen, Switzerland (2002).

3. ONDRAF: SAFIR 2: Safety assessment and feasibility interim report 2. NIROND-2001-06 E. ONDRAF, Brussels, Belgium (2001).

4. Baeyens, B., Bradbury, M. H.: A mechanistic description of Ni and $\mathrm{Zn}$ sorption on Na-montmorillonite. 1. Titration and sorption measurements. J. Contam. Hydrol. 27, 199 (1997).

5. Bradbury, M. H., Baeyens, B.: A mechanistic description of $\mathrm{Ni}$ and $\mathrm{Zn}$ sorption on Na-montmorillonite. 2. Modelling. J. Contam. Hydrol. 27, 223 (1997).

6. Bradbury, M. H., Baeyens, B.: A quasi-mechanistic non-electrostatic modelling approach to metal sorption on clay minerals. In: Surface Complexation Modelling. (Lützenkirchen, J., ed.) Elsevier, Amsterdam (2006), p. 518.

7. Bradbury, M. H., Baeyens, B.: Modelling sorption data for the actinides $\mathrm{Am}(\mathrm{III}), \mathrm{Np}(\mathrm{V})$ and $\mathrm{Pa}(\mathrm{V})$ on montmorillonite. Radiochim. Acta 94, 619 (2006).

8. Bradbury, M. H., Baeyens, B.: Sorption of Eu on Na- and Camontmorillonites: Experimental investigations and modelling with cation exchange and surface. Geochim. Cosmochim. Acta 66, 2325 (2002).

9. Grim, R. E.: Clay Mineralogy. McGraw Hill, New York (1953).

10. Sposito, G.: The Surface Chemistry of Soils. Oxford University Press, New York (1984).

11. Gaines, G. L., Thomas, H. C.: Adsorption studies on clay. II. A formulation of the thermodynamics of exchange adsorption. J. Chem. Phys. 21, 714 (1953).

12. Bradbury, M. H., Baeyens, B.: PSI Bericht Nr. 95-12. Paul Scherrer Institut, Villigen and Nagra Technical Report NTB 95-06, Nagra, Wettingen, Switzerland (1995).

13. Westall, J., Zachary, J. L., Morel, F.: MINEQL, a computer program for the calculation of chemical equilibrium composition of aquous systems. Technical Note 18 (1976).

14. Neck, V., Fanghänel, T., Kim, J. I.: Aquatische Chemie und thermodynamische Modellierung von trivalenten Actiniden. Technik und Umwelt, Forschungszentrum Karlsruhe (1998).

15. Guillaumont, R., Fanghänel, T., Fuger, J., Grenthe, I., Neck, V., Palmer, D. A., Rand, M. H.: OECD-NEA Chemical Thermodynamics, Vol. 5. Update on the Chemical Thermodynamics of Uranium, Neptunium, Plutonium, Americium and Technetium. Elsevier, Amsterdam (2003). 
16. Baeyens, B., Bradbury, M. H.: A quantitative mechanistic description of $\mathrm{Ni}, \mathrm{Zn}$ and $\mathrm{Ca}$ sorption on Na-montmorillonite. PSI Bericht Nr. 95-10 (1995).

17. Baeyens, B., Bradbury, M. H.: Cation exchange capacity measurements on illite using the sodium and cesium isotope dilution technique. Effects of the index cation, electrolyte concentration and competition: modeling. Clays Clay Min. 52, 421 (2004).

18. Perrin, D. D., Dempsey, B.: Buffers for $\mathrm{pH}$ and Metal Ion Control. Chapman and Hall, London (1974).

19. Meinrath, G., Kim, J. I.: The carbonate complexation of the Am(III) ion. Radiochim. Acta 52(3), 29 (1991).

20. Rabung, T., Pierret, M. C., Bauer, A., Geckeis, H., Bradbury, M. H., Baeyens, B.: Sorption of Eu(III)/Cm(III) on Ca-montmorillonite and Na-illite. Part 1: Batch sorption and time-resolved laser fluo- rescence spectroscopy experiments. Geochim. Cosmochim. Acta 69, 5393 (2005).

21. Stumpf, T., Hennig, C., Bauer, A., Denecke, M. A., Fanghänel, T.: An EXAFS and TRLFS study of the sorption of trivalent actinides onto smectite and kaolinite. Radiochim. Acta 92, 133 (2004).

22. Stumpf, T., Bauer, A., Coppin, F., Fanghanel, T., Kim, J. I.: Innersphere, outer-sphere and ternary surface complexes: a TRLFS study of the sorption process of $\mathrm{Eu}(\mathrm{III})$ onto smectite and kaolinite. Radiochim. Acta 90, 345 (2002).

23. Nolin D., Rétention de radioéléments a vie longue par des matériaux argileux-influence d'anions contenus dans les eaux naturelles. In: Chimie Analytique. Université Pierre et Marie Curie, Paris (1997), p. 219. 